\title{
Racial and Ethnic Disparities in Adverse Drug Events: A Systematic Review of the Literature
}

\author{
Avi Baehr ${ }^{1,2}$ • Juliet C. Peña ${ }^{1}$ Dale J. Hu ${ }^{1}$
}

Received: 18 November 2014 / Revised: 19 January 2015 / Accepted: 27 February 2015 /Published online: 24 March 2015

(C) W. Montague Cobb-NMA Health Institute 2015

\begin{abstract}
The 2014 National Action Plan for Adverse Drug Event Prevention has recognized adverse drug events (ADEs) as a national priority in order to facilitate a nationwide reduction in patient harms from these events. Throughout this effort, it will be integral to identify populations that may be at particular risk in order to improve care for these patients. We have undertaken a systematic review to evaluate the evidence regarding racial or ethnic disparities in ADEs with particular emphasis on anticoagulants, diabetes agents, and opioids due to the clinical significance and preventability of ADEs associated with these medication classes. From an initial search yielding 3302 studies, we identified 40 eligible studies. Twenty-seven of these included studies demonstrated the presence of a racial or ethnic disparity. There was no consistent evidence for racial or ethnic disparities in the eight studies of ADEs in general. Asians were most frequently determined to be at higher risk of anticoagulant-related ADEs, and black patients were most frequently determined to be at higher risk for diabetes agents-related ADEs. Whites were most frequently identified as at increased risk for opioid-related ADEs. However, few of these studies were specifically designed to evaluate racial or ethnic disparities, lacking a standardized
\end{abstract}

Electronic supplementary material The online version of this article (doi:10.1007/s40615-015-0101-3) contains supplementary material, which is available to authorized users.

Avi Baehr

avigile.baehr@hhs.gov

1 Division of Health Care Quality, Office of Disease Prevention and Health Promotion, US Department of Health and Human Services, 1101 Wootton Parkway, Suite 200, Rockville, MD 20852, USA

2 Perelman School of Medicine at the University of Pennsylvania, Philadelphia, PA, USA approach to racial/ethnic categorization as well as control for potential confounders. We suggest the need for targeted interventions to reduce ADEs in populations that may be at increased risk, and we suggest strategies for future research.

Keywords Adverse drug events $\cdot$ Patient safety $\cdot$ Health care quality $\cdot$ Health care disparities

\section{Introduction}

Racial and ethnic health disparities have been demonstrated in a number of health care quality and patient safety domains, including preventable hospitalizations [1] and health careassociated infections [2]. The need to reduce these differences and improve the quality of health care for vulnerable populations has been highlighted in the 2011 HHS Action Plan to Reduce Racial and Ethnic Health Disparities [3]. One important area in health care quality and patient safety is adverse drug events (ADEs), which are defined as injuries "resulting from medical intervention related to a drug" and include medication errors, allergic reactions, and side effects [4]. These events were highlighted nearly 15 years ago in a landmark report by the Institute of Medicine (IOM) as a major contributor to avoidable health care-associated morbidity and mortality [4]. Although these events remain a significant barrier to patient safety, they are often preventable, especially among certain key drug classes [5]. Since the IOM report, a number of factors, such as an increasing proportion of older individuals as well as changing patterns in medication use, have contributed to an increase in exposure to prescription medications. From 2007 to 2010, nearly one half of all Americans reported taking at least one prescription drug in the past 30 days, and an increasing proportion of Americans reported using five or more drugs in the past month [6]. Not 
surprisingly, the incidence of ADEs has also increased during this time, and in 2008 , these events were implicated in nearly two million inpatient stays and were reported in over 800,000 emergency department treat-and-release visits [7].

Accordingly, the 2014 National Action Plan for Adverse Drug Event Prevention was recently established to highlight ADEs as a national patient safety priority and to facilitate a nationwide reduction in patient harms from these events. The 2014 National Action Plan identifies three high-impact medication classes of narrow therapeutic index in which ADEs are common, clinically significant, preventable, and measurable: anticoagulants, diabetes agents, and opioids. The 2014 National Action Plan proposes a four-pronged approach in reducing these adverse events, involving surveillance, prevention, incentives and oversight, and research. Throughout this approach, one important goal is to identify patient populations that may be at relatively higher risk for ADEs in order to target efforts towards reducing these disparities [5]. Given the demonstrated impact of adverse drug events, we believe that this is a key patient safety area in which to evaluate the presence of any racial or ethnic disparities. The goals of this review were as follows: (1) to synthesize existing literature in order to understand the state of evidence for racial and ethnic disparities associated with ADEs in the USA and (2) to identify gaps in existing knowledge in order to target future research.

\section{Methods}

\section{Inclusion Criteria and Literature Search}

A literature search was conducted using PubMed and EMBASE with title and abstract search terms including the following: adverse drug event(s), adverse medication event(s), hypoglycem(ia/ic), opioid(s), anticoagula(tion/nt), race, racial, ethnic(ity), disparit(y/ies), inequalit(y/ies), and safety. Results were limited to original research published in the English language. Populations of interest included non-pregnant patients older than 1 year of age in the USA or its territories. Outcomes of interest included any adverse drug event. The review was targeted to examine ADEs in general as well as ADEs related to the three drug classes highlighted in the 2014 National Action Plan [5]. Specifically, outcomes of interest associated with target drug classes included bleeding events associated with anticoagulation, supratherapeutic anticoagulation, hypoglycemia associated with diabetes agents, respiratory depression and oversedation associated with opioids, and gastrointestinal distress and pruritus associated with opioids.

Studies were excluded from further review if they did not provide quantitative data on ADEs with a risk comparison between at least two racial or ethnic groups within the USA or if they did not analyze either ADEs in general or focus on any of the target drug classes. We limited our analysis to studies within the USA in order to best capture potential racial or ethnic disparities within the context of this country's particular racial/ethnic groups and historical factors. Because we defined ADEs as events related to drugs used in medical interventions, studies focusing on intentional abuse or misuse of medications were excluded.

PubMed and EMBASE databases were queried by one reviewer $(\mathrm{AB})$, and unique results were compiled. Two independent reviewers $(\mathrm{AB}$ and $\mathrm{JP})$ screened titles and abstracts for eligibility, and studies were eliminated from further review if both reviewers agreed on their exclusion. Remaining studies were reviewed in full text by two independent reviewers $(\mathrm{AB}$ and JP) on the basis of pre-determined eligibility criteria. Final eligibility determinations were compared between the two reviewers, and any disagreements were settled by consensus. Additional studies were identified by reviewing reference lists of eligible studies and from a Google search, and these were reviewed by both reviewers to determine eligibility (see Online Resource 1 for detailed search methodology).

\section{Data Analysis and Reporting}

Two reviewers (AB and JP) individually abstracted data from eligible studies, including data source, population studied, outcome(s) evaluated, sample size, racial/ethnic groups, disparity identified (yes/no), and at-risk racial/ethnic group with quantification.

Given the heterogeneity of the collection and reporting of race and ethnicity data, the racial/ethnic groups were simplified and consolidated as follows: white to include Caucasian and non-Hispanic white; black to include African American and non-Hispanic black; Hispanic to include Latino; Asian to include Asian/Pacific Islander; American Indian to include Native American; unspecified minority to include aggregated non-white; and other to include individuals with missing racial/ethnic data and/or persons of mixed racial/ethnic heritage or groups not otherwise included above. These simplified racial/ethnic groups were based on the most common categories used in the included studies.

A racial/ethnic disparity was identified to be present when a study reported that a specific racial/ethnic status was significantly associated with the risk of ADEs following statistical analysis. When available, the results of multivariate logistic regression were abstracted as the preferred method of disparity quantification. For each study that demonstrated a disparity, the at-risk racial/ethnic group was defined as the group that was associated with the highest incidence or risk of the ADE. Studies that demonstrated a risk difference only affecting the "other" group were not considered to have identified a disparity for the purposes of data abstraction. This requirement allowed us to isolate the studies that identified meaningful at-risk groups for ADEs. 


\section{Results}

Initial queries of PubMed and EMBASE databases by one reviewer $(\mathrm{AB})$ yielded 4062 studies, and nine additional studies were identified by reviewing relevant works cited in the eligible studies and from a targeted Google search. Forty studies were determined to be eligible for inclusion in the systematic literature review (Fig. 1), with $96 \%$ agreement between two reviewers (Online Resource 1). Eight of the included studies analyzed ADEs in general, 8 studies analyzed anticoagulant-related ADEs, 16 analyzed ADEs related to diabetes agents, and 9 studies analyzed opioid-related ADEs. One study analyzed ADEs related to both anticoagulants and diabetes agents [8].

While the majority of the included studies were retrospective cohort studies, there was significant heterogeneity in methodologies. Primary ADE detection methods were categorized as follows: (1) administrative claims data including cause of death coding, (2) chart review including electronic health records and laboratory data, (3) patient or parent report or survey, and (4) prospective documentation by research staff. ADE verification methods included secondary confirmation of an ADE utilizing any of the above detection methods: for example, a study might have used laboratory data in order to confirm an ADE that was primarily identified by administrative claims coding.

Each of the first three ADE detection methods was utilized in approximately one third of included studies. Administrative claims data were the most common sources of primary ADE detection, used in $37.5 \%(15 / 40)$ of studies [9-23]. Chart review was used as a primary ADE detection method in $35 \%(14 / 40)$ of studies [8, 24-36], and survey or patient/ parent report was used in $27.5 \%$ (11/40) of the studies [27, $32,33,37-44]$. Direct documentation by research staff was used by three studies $(7.5 \%)$ [45-47]. Three studies $(7.5 \%)$ used more than one method for ADE detection [27, 32, 33]; two of these studies that analyzed agreement between methods of ADE detection found that only 5-6\% of ADEs were detected by both chart review and patient report [27, 33]. In contrast to using more than one method for ADE detection, an additional three studies utilized chart review as a secondary method only for ADE verification [14, 20, 42].

All eligible studies included white patients in their analysis, although two studies aggregated data from other racial/ethnic groups within this group. White patients made up the majority of the sample size in 33 of the studies (Online Resource Tables S1, S2, S3, and S4). The majority of studies (90\%) included black patients as a separate group in their analysis, and half included Hispanics (Fig. 2). Two of these studies analyzed Hispanics as compared to non-Hispanics, including both blacks and whites in each group [17, 32].

Thirteen studies (32.5\%) analyzed national datasets [8-13, $17-19,21,36,38,40]$, of which seven analyzed nationally representative samples. Only two of these studies included patients of all ages. Twenty-seven studies $(67.5 \%)$ identified a racial or ethnic disparity (Online Resource Tables S1, S2,

Fig. 1 Literature review process

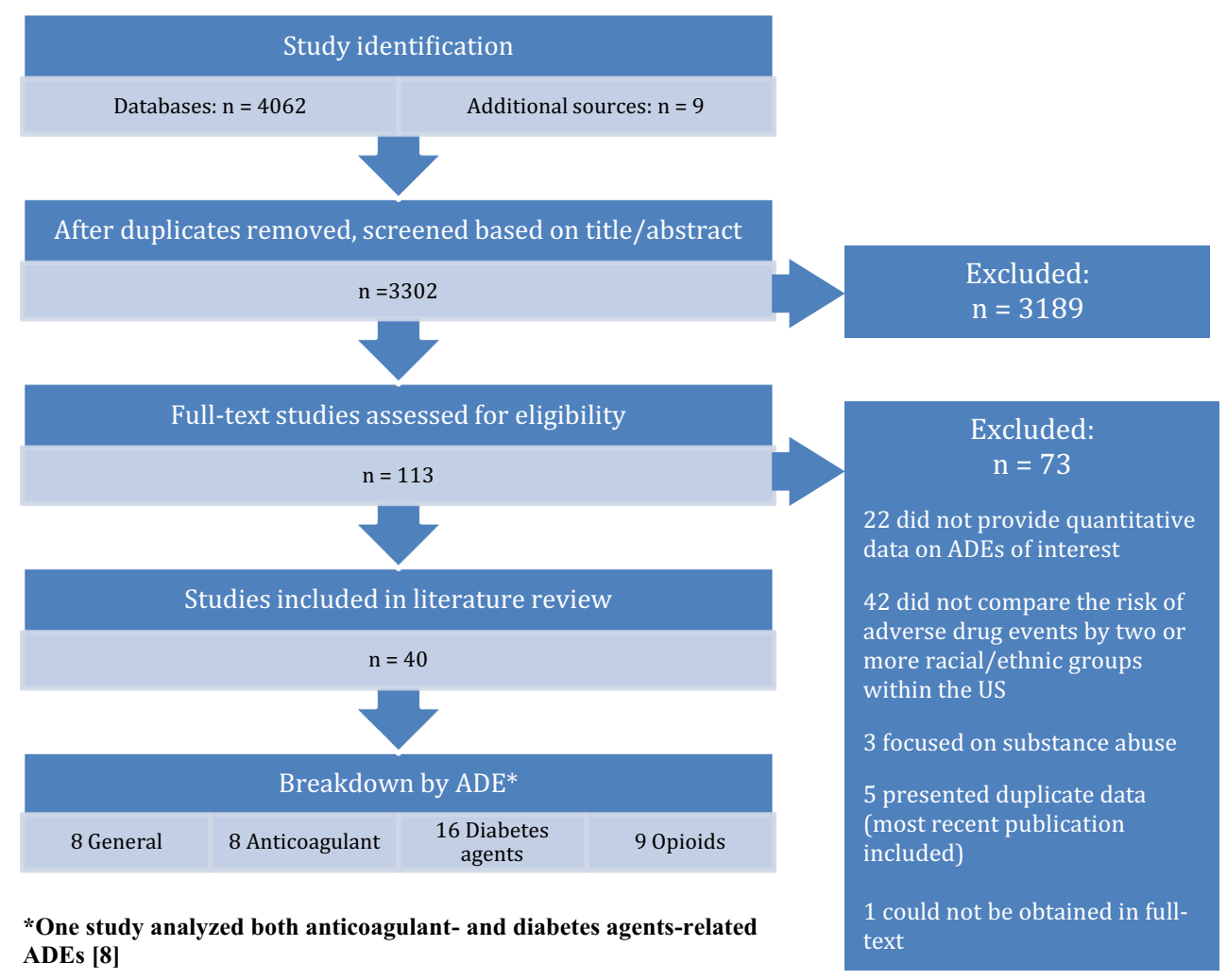


Fig. 2 Percent of studies that included specified racial/ethnic groups in the analysis of adverse drug events $(N=40)$

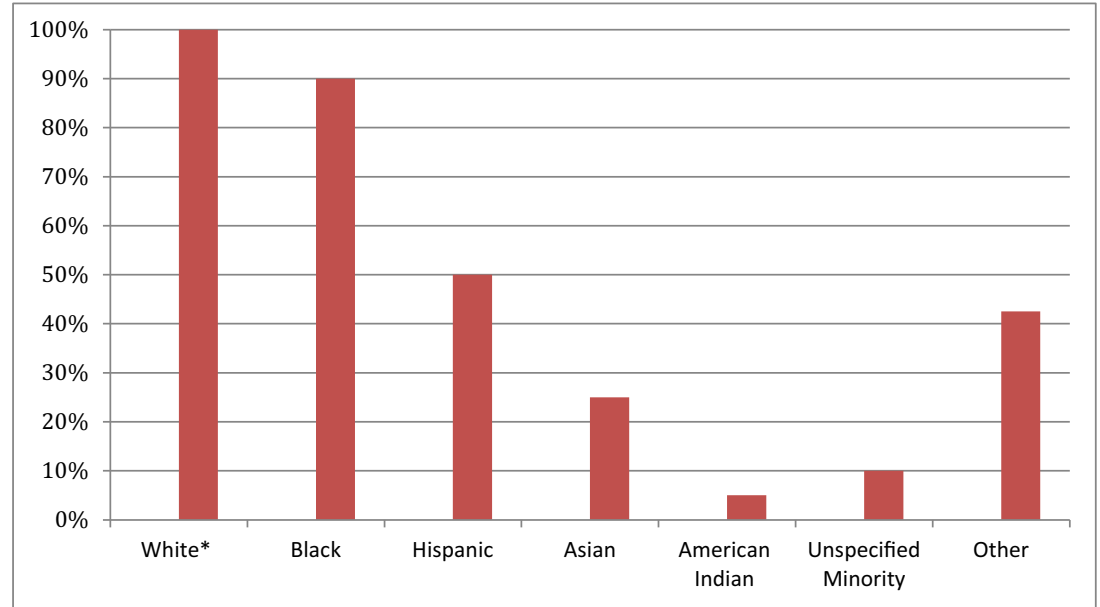

*Referent race; includes studies that aggregated Whites with other racial/ethnic groups, if Whites represented the majority of the group.
S3, and S4), of which 21 identified a minority group as the atrisk group. Racial or ethnic disparities were demonstrated in studies of inpatient, outpatient, and emergency department populations.

\section{General Adverse Drug Events}

Two of the eight studies examining ADEs in general (25\%) did identify a racial or ethnic disparity (Table 1). Both of these were studies of elderly inpatients in a national dataset; of interest, however, one of these studies identified blacks to be at risk (odds ratio [OR] 1.38, $95 \%$ confidence interval [CI] 1.23-1.54) [12] and the other identified whites as at higher risk (OR 1.18, $95 \%$ CI 1.18-1.18) compared to non-whites [11]. Although both studies analyzed ADEs using administrative claims data, these two studies were distinct in methodology and outcomes measured: the former analyzed the outcome of drug-related harms, including accidental overdose and adverse effects in therapeutic use, while the latter analyzed the outcome of deaths due to adverse effects of drugs in therapeutic use. Neither of those two studies adjusted for any socioeconomic factors. None of the five studies that analyzed
ADEs in the outpatient or emergency department setting demonstrated a disparity (Online Resource Table S1).

\section{Anticoagulant-Related Adverse Drug Events}

Of the eight studies analyzing anticoagulant-related ADEs, six studies assessed bleeding as an outcome and three assessed supratherapeutic anticoagulation. Five of these studies $(62.5 \%)$ found a racial or ethnic disparity to be present (Table 2). Asian patients were most frequently identified as at increased risk for anticoagulantrelated ADEs, including both bleeding events and supratherapeutic anticoagulation: three of the four studies that included this group found that Asian race was associated with an approximately fourfold risk of anticoagulant-related ADEs. The other study including Asians found that this group might spend less time above therapeutic anticoagulation range (13.5 vs $16.1 \%$ in whites), although this result was not statistically significant [25]. Two studies also found black patients to be at increased risk of anticoagulation-related ADEs compared to white patients, although the magnitude of the potential

Table 1 Summary of the evidence for racial or ethnic disparities in general ADEs

\begin{tabular}{llll}
\hline Racial/ethnic group & Studies that analyzed the group & $\begin{array}{l}\text { Studies that identified } \\
\text { the group as at risk }{ }^{\mathrm{a}}\end{array}$ & Risk quantification (95 \% CI) \\
\hline White & $8[9-12,27,28,31,33]$ & 1 & OR 1.18 (1.18-1.18) compared to non-whites [11] \\
Black & $6[9,10,12,27,31,33]$ & 1 & OR 1.38 (1.23-1.54) compared to whites [12] \\
Hispanic & $5[9,10,12,27,33]$ & 0 & OR 0.43 (0.37-0.52) compared to whites [12] \\
Asian & $2[12,27]$ & 0 & OR 0.34 (0.25-0.47) compared to whites [12] \\
American Indian & $1[12]$ & 0 & $0.44(0.24-0.79)$ compared to whites [12] \\
Unspecified minority & $2[11,28]$ & 0 & -
\end{tabular}

$C I$ confidence interval, $H R$ hazard ratio, $O R$ odds ratio

${ }^{a}$ At-risk racial/ethnic group was defined as the group that was associated with the highest incidence or point estimate of risk of the ADE 


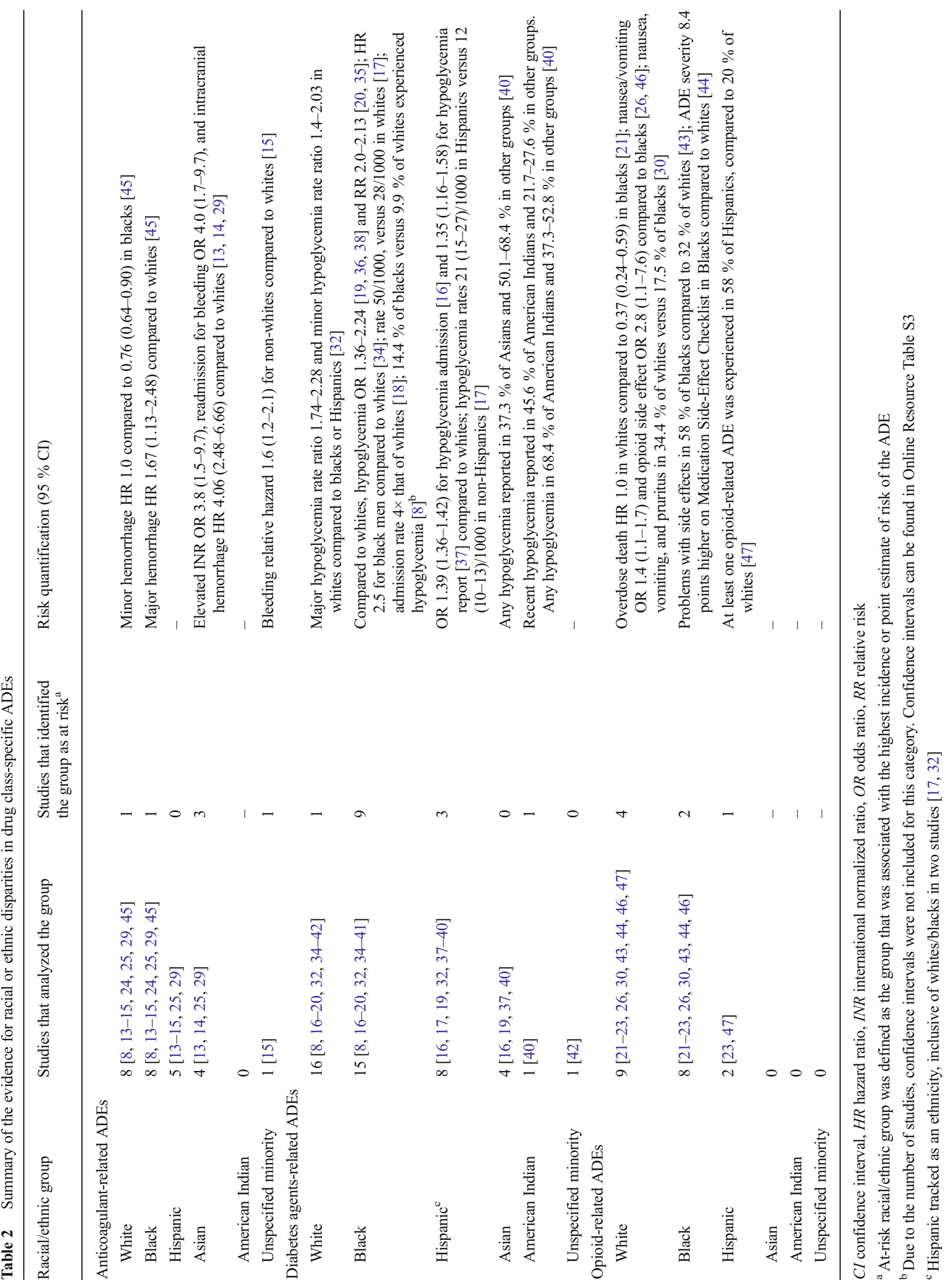


disparity was lower than that for Asians [14, 45]. Six studies analyzed ADEs in the inpatient setting and two studies analyzed outpatient settings, and results were variable across clinical settings (Online Resource Table S2).

\section{Diabetes Agents-Related Adverse Drug Events}

Hypoglycemia was the outcome of interest in all of the 16 included studies that examined diabetes agents-related ADEs, but definitions were highly variable. Of the studies that included a blood glucose measurement in the hypoglycemia definition, measurements ranged from 50 to $70 \mathrm{mg} / \mathrm{dL}$. Clinical definitions included loss of consciousness, requiring assistance from another person, and hospital admission (Online Resource Table S3). Thirteen studies (81.2 \%) demonstrated a racial or ethnic disparity. Blacks were the at-risk racial group in nine of these studies, and they were at increased risk compared to whites in 11 studies. The magnitude of increased risk ranged from approximately 1.25 to 2.5 (Online Resource Table S3). One study found that blacks had a fourfold higher admission rate for hypoglycemia, but this study did not control for the higher prevalence of diabetes in blacks [18]. American Indians were found to be at increased risk for hypoglycemia in the one study that analyzed this group separately. Two of the four studies that included Asians demonstrated them to be at increased risk compared to whites, with OR 1.28 (95\% CI 1.09-1.51) for report of hypoglycemia [37] and OR 1.15 (95\% CI 1.03-1.75) for acute hypoglycemia admissions [19]. One study found this group to be at decreased risk for diabetes agents-related ADEs, with $37.3 \%$ of Asian participants reporting ever experiencing hypoglycemia, while over $50 \%$ of the other racial or ethnic groups reported this outcome [40]. Eight studies analyzed ADEs in the inpatient setting, eight in the outpatient setting, and two in the emergency department. The three studies that did not demonstrate a racial or ethnic disparity all analyzed patients in the outpatient setting, detected ADEs via survey or report, and had relatively small sample sizes of less than 600 participants [39, 41, 42].

\section{Opioid-Related Adverse Drug Events}

Nine studies examined opioid-related ADEs. None of these studies examined a nationally representative database. Four of the studies assessed side effects in general; three studies assessed nausea, vomiting, or respiratory depression; one study assessed constipation; and one study assessed death. Seven studies $(77.8 \%)$ demonstrated a racial or ethnic disparity, with whites identified as at increased risk in four of these studies (Table 2). Of the eight studies that included blacks, the only two studies that identified ADEs by survey or patient report both found blacks to be at higher risk for opioidrelated side effects $[43,44]$. One of the three studies
(33.3 \%) that analyzed Hispanics found this group to be at increased risk of side effects (Table 2). Four studies analyzed ADEs in the inpatient setting, three in the outpatient setting, and two in ambulatory surgery centers (Online Resource Table S4).

\section{Discussion}

Racial and ethnic disparities have been widely reported across the continuum of health, from disease prevention to health care access to patient safety and quality of care. While continued efforts towards correcting all of these health inequalities remain of utmost importance, the 2014 National Action Plan has highlighted ADEs as a national patient safety and health care quality priority [5]. The 2014 Nation Action Plan has recognized that certain populations might bear a disproportionate burden of ADEs, and it calls for a better understanding of these potential disparities.

While other literature reviews have examined racial or ethnic disparities in ADEs, these reviews have been limited by the inclusion of few studies [48] or the focus on a single medication class [49]. To our knowledge, this is the first systematic literature review to examine the state of evidence for racial or ethnic disparities in ADEs, both in general and with particular emphasis on the high-impact drug classes as outlined in the 2014 National Action Plan.

Twenty-seven of the 40 eligible studies demonstrated a racial or ethnic disparity, of which 21 identified a minority group as at risk. Sample sizes varied widely, however, and some of these studies might not have been adequately powered to detect any potential disparity. Although results were variable, Asians were most commonly identified as the at-risk group for anticoagulant-related ADEs and blacks were the most commonly identified group at risk for ADEs caused by diabetes agents. Whites were most frequently identified as at risk for opioid-related ADEs.

We identified limitations of research conducted to date regarding racial or ethnic disparities in ADEs. Most studies did not evaluate a nationally representative sample, and there was not a standardized approach to categorizing race or ethnicity. Many studies aggregated data from multiple racial or ethnic groups (e.g., non-white [11, 28, 42]), and the vast majority of studies did not include more detailed breakdowns of ethnicity by ancestry.

Furthermore, few of the included studies were specifically designed to evaluate the underlying factors that may have contributed to an identified racial or ethnic disparity: income, education, and geographical location were only analyzed in a minority of studies. Many of the studies excluded patients who did not speak English as their primary language, which may have led to underestimation of ADE rates among groups that have lower rates of English proficiency. 
There were also significant limitations in the detection of ADEs. Administrative claims data has been demonstrated to grossly underestimate the incidence of ADEs [50-52]. Retrospectively detecting ADEs by chart review relies on provider recognition and documentation of the event, which also likely underestimates the true incidence and prevalence of ADEs. It has been proposed that the available methods for detecting ADEs might capture different categories of events, thus suggesting a complementary role for multiple ADE detection strategies [53]. However, only $7.5 \%$ of the included studies used more than one method to detect ADEs. While this points to a much larger issue in ADE detection, it is not likely that this study limitation disproportionately affected a particular racial or ethnic group. We suggest the need for improved ADE detection methods, such as computer-based monitoring systems and increased electronic health record integration [5].

Limitations of our study itself include the exclusion of studies unavailable via PubMed or EMBASE and potential reviewer bias in identifying studies for consideration. Although we believe that we developed a sound and detailed methodology, it is still possible that we omitted some studies relevant to our analysis. The rationale for using electronic and common databases was that these sources were easily accessible and allowed for more efficient search filtering. The use of pre-determined inclusion and exclusion criteria, along with the high degree of agreement between two independent reviewers, makes it less likely that reviewer bias significantly impacted the results of our study.

Our study was also limited by the heterogeneity of results. Included studies differed in their approaches to categorizing patient race/ethnicity, ADE definitions and detection methods, and statistical analyses. Furthermore, studies spanned care settings and frequently did not differentiate between events occurring in the hospital or emergency department and those that first manifested in the outpatient setting. This heterogeneity, along with the relatively small number of eligible studies, limited our ability to further stratify the studies and analyze potential patterns in or contributing factors to the variable results. However, we recognize that the contributing factors for ADEs, and therefore for any potential racial/ethnic disparities, vary by care settings. In the future, a more standardized approach should be taken to study ADEs in different settings and populations, and stratification by site of ADE occurrence would be useful to inform prevention strategies.

Our study has identified critical gaps in the literature regarding racial or ethnic disparities in ADEs. Sensitive identification of ADEs remains a challenge, and $92.5 \%$ of the studies that we included for analysis did not utilize a multimodal approach to ADE detection. Racial and ethnic data collection and reporting were neither comprehensive nor standardized, which makes it difficult to compare results across studies. Inadequate data on race/ethnicity and language can also obscure existing disparities and decreases the likelihood of effective actions to address health disparities, as emphasized by a 2009 IOM report [54]. There was no standardized approach to determining the contribution of potential confounders. Accordingly, we are unable to conclude what, if any, factors contributed to or accounted for the observed disparities. Genetics, food insecurity, and health literacy, for example, have been linked to increased risk of ADEs in certain populations [55-57].

Given the heterogeneity of the included studies, it is not surprising that the study results were highly variable. As a result, the generalizability and validity of currently available data are limited. Despite these limitations, our findings have implications for health policy and clinical practice. While we have demonstrated the need for further studies specifically designed to evaluate racial and ethnic disparities in ADEs, we have also demonstrated several potential disparities:

1. Asians may be at particular risk for anticoagulant-related ADEs. Pharmacogenomic studies have suggested that certain polymorphisms may contribute to increased warfarin sensitivity in Asians [55]. However, there is insufficient evidence to support the clinical utility of genetic testing prior to warfarin initiation [58]. Non-vitamin K antagonists have been proposed as a potentially safer option for anticoagulation in Asians [59], but more research is needed to determine the risks and benefits of these newer medications.

2. Blacks may be at increased risk for diabetes agents-related ADEs. The potential influence of patient race on diabetes management has been previously demonstrated. Black patients have been demonstrated to have lower rates of health literacy [57], which is a demonstrated risk factor for hypoglycemia [60]. In addition, race may impact a clinician's choice of diabetes agents and changes in regimens [61]. In the pediatric population, minority children were shown to be less likely than white children to receive diabetes management support in school [62].

3. In contrast to the more frequently reported instances where white patients may be at lower risk of certain adverse events, whites may be at increased risk for opioid-related ADEs. This effect may be due to a number of factors, including previously demonstrated disparities in pain management between whites and blacks [63]. While the potential undertreatment of pain in blacks remains a critical health care quality issue, it is also important to consider the impact of ADEs related to overtreatment, particularly in whites. In addition to the difference in pain management, less frequent monitoring of white patients [63] may also account for different rates of opioid-related ADEs. 


\section{Recommendations}

In conclusion, we have demonstrated significant gaps in the literature regarding racial or ethnic disparities in ADEs. We have also demonstrated significant limitations in race/ ethnicity reporting and ADE identification. We have highlighted several potential drug class-specific disparities, and we have suggested the need for targeted interventions. More research is needed in order to specifically tailor prevention strategies towards the most vulnerable groups for different ADEs, and we make the following recommendations in conducting further research: (1) use consistent and meaningful racial and ethnic definitions and (2) promote the evaluation of underlying factors that may be responsible for $\mathrm{ADE}$ disparities.

Acknowledgments This research was supported in part by an appointment to the Research Participation Program at the US Department of Health and Human Services administered by the Oak Ridge Institute for Science and Education.

\section{Compliance with Ethical Standards}

Conflict of Interest Authors Baehr, Peña, and Hu declare that they have no conflicts of interest. The views expressed herein are those of the authors and do not necessarily reflect the views of the US Department of Health and Human Services.

Ethical Standards For this type of study, formal consent is not required. This article does not contain any studies with human participants or animals performed by any of the authors.

\section{References}

1. CDC health disparities and inequalities report-United States. Morbidity and Mortality Weekly Report: US Department of Health and Human Services, Centers for Disease Control and Prevention 2011 January 14.

2. Bakullari A, Metersky ML, Wang Y, Eldridge N, Eckenrode S, Pandolfi MM, et al. Racial and ethnic disparities in healthcareassociated infections in the United States, 2009-2011. Infect Control Hosp Epidemiol Off J Soc Hosp Epidemiol Am. 2014;35 Suppl 3:S10-6. doi:10.1086/677827.

3. Koh HK, Graham G, Glied SA. Reducing racial and ethnic disparities: the Action Plan from the Department of Health and Human Services. Health Aff. 2011;30(10):1822-9. doi:10.1377/hlthaff. 2011.0673.

4. Kohn LT, Corrigan JM, Donaldson MS. To err is human: building a safer health system. Washington: Institute of Medicine; 2000.

5. National Action Plan for Adverse Drug Event Prevention. Washington, DC: Office of Disease Prevention and Health Promotion, US Department of Health and Human Services 2014.

6. National Center for Health Statistics. Health, United States, 2013: with special feature on prescription drugs. Hyattsville, MD 2014.

7. Lucado J, Paez K, Elixhauser A. Medication-related adverse outcomes in US hospitals and emergency departments. Rockville: Healthcare Cost and Utilization Project, AHRQ; 2011.

8. Metersky ML, Hunt DR, Kliman R, Wang Y, Curry M, Verzier N, et al. Racial disparities in the frequency of patient safety events: results from the national medicare patient safety monitoring system. Med Care. 2011;49(5):504-10. doi:10.1097/MLR. 0b013e31820fc218.

9. Bourgeois FT, Shannon MW, Valim C, Mandl KD. Adverse drug events in the outpatient setting: an 11-year national analysis. Pharmacoepidemiol Drug Saf. 2010;19(9):901-10. doi:10.1002/ pds. 1984.

10. Sarkar U, Lopez A, Maselli JH, Gonzales R. Adverse drug events in U.S. adult ambulatory medical care. Health Serv Res. 2011;46(5): 1517-33. doi:10.1111/j.1475-6773.2011.01269.x.

11. Shamliyan TA, Kane RL. Drug-related harms in hospitalized medicare beneficiaries: results from the healthcare cost and utilization project, 2000-2008. J Patient Saf. 2014. doi:10.1097/PTS. 0000000000000106.

12. Shepherd G, Mohorn P, Yacoub K, May DW. Adverse drug reaction deaths reported in United States vital statistics, 1999-2006. Ann Pharmacother. 2012;46(2):169-75. doi:10.1345/aph.1P592.

13. Moffett BS, Kim S, Bomgaars LR. Readmissions for warfarinrelated bleeding in pediatric patients after hospital discharge. Pediatr Blood Cancer. 2013;60(9):1503-6. doi:10.1002/pbc.24546.

14. Shen AY, Yao JF, Brar SS, Jorgensen MB, Chen W. Racial/ethnic differences in the risk of intracranial hemorrhage among patients with atrial fibrillation. J Am Coll Cardiol. 2007;50(4):309-15. doi: 10.1016/j.jacc.2007.01.098.

15. White RH, Beyth RJ, Zhou H, Romano PS. Major bleeding after hospitalization for deep-venous thrombosis. Am J Med. 1999;107(5):414-24.

16. Asuncion MM, Shaheen M, Ganesan K, Velasques J, Teklehaimanot S, Pan D, et al. Increase in hypoglycemic admissions: California hospital discharge data. Ethn Dis. 2007;17(3): 536-40.

17. Ginde AA, Espinola JA, Camargo Jr CA. Trends and disparities in U.S. emergency department visits for hypoglycemia, 1993-2005. Diabetes Care. 2008;31(3):511-3. doi:10.2337/dc07-1790.

18. Lipska KJ, Ross JS, Wang Y, Inzucchi SE, Minges K, Karter AJ, et al. National trends in US hospital admissions for hyperglycemia and hypoglycemia among Medicare beneficiaries, 1999 to 2011. JAMA Intern Med. 2014;174(7):1116-24. doi:10.1001/ jamainternmed.2014.1824.

19. Shen JJ, Washington EL. Identification of diabetic complications among minority populations. Ethn Dis. 2008;18(2):136-40.

20. Shorr RI, Ray WA, Daugherty JR, Griffin MR. Incidence and risk factors for serious hypoglycemia in older persons using insulin or sulfonylureas. Arch Intern Med. 1997;157(15):1681-6.

21. Bohnert AS, Valenstein M, Bair MJ, Ganoczy D, McCarthy JF, Ilgen MA, et al. Association between opioid prescribing patterns and opioid overdose-related deaths. JAMA J Am Med Assoc. 2011;305(13):1315-21. doi:10.1001/jama.2011.370.

22. Kessler ER, Shah M, Gruschkus SK, Raju A. Cost and quality implications of opioid-based postsurgical pain control using administrative claims data from a large health system: opioid-related adverse events and their impact on clinical and economic outcomes. Pharmacotherapy. 2013;33(4):383-91. doi:10.1002/phar.1223.

23. Staats PS, Markowitz J, Schein J. Incidence of constipation associated with long-acting opioid therapy: a comparative study. South Med J. 2004;97(2):129-34. doi:10.1097/01.SMJ.0000109215. 54052.D8.

24. Aujesky D, Long JA, Fine MJ, Ibrahim SA. African American race was associated with an increased risk of complications following venous thromboembolism. J Clin Epidemiol. 2007;60(4):410-6. doi:10.1016/j.jclinepi.2006.06.023.

25. Bhandari VK, Wang F, Bindman AB, Schillinger D. Quality of anticoagulation control: do race and language matter? J Health Care Poor Underserved. 2008;19(1):41-55. doi:10.1353/hpu. 2008.0002 . 
26. Cepeda MS, Farrar JT, Baumgarten M, Boston R, Carr DB, Strom BL. Side effects of opioids during short-term administration: effect of age, gender, and race. Clin Pharmacol Ther. 2003;74(2):102-12. doi:10.1016/S0009-9236(03)00152-8.

27. Gandhi TK, Burstin HR, Cook EF, Puopolo AL, Haas JS, Brennan TA, et al. Drug complications in outpatients. J Gen Intern Med. 2000;15(3):149-54.

28. Hafner Jr JW, Belknap SM, Squillante MD, Bucheit KA. Adverse drug events in emergency department patients. Ann Emerg Med. 2002;39(3):258-67.

29. Moffett BS, Ung M, Bomgaars L. Risk factors for elevated INR values during warfarin therapy in hospitalized pediatric patients. Pediatr Blood Cancer. 2012;58(6):941-4. doi:10.1002/pbc.23308.

30. Son-Hing JP, Poe-Kochert C, Thompson GH, Potzman J, Tripi PA. Intrathecal morphine analgesia in idiopathic scoliosis surgery: does sex or racial group affect optimal dosing? J Pediatr Orthop. 2011;31(5):489-95. doi:10.1097/BPO.0b013e3182203988.

31. Taber DJ, Pilch NA, Bratton CF, McGillicuddy JW, Chavin KD, Baliga PK. Medication errors and adverse drug events in kidney transplant recipients: incidence, risk factors, and clinical outcomes. Pharmacotherapy. 2012;32(12):1053-60. doi:10.1002/phar.1145.

32. Trippe BS, Shepherd MD, Coulter FC, Bhargava A, Brett J, Chu PL, et al. Efficacy and safety of biphasic insulin aspart 70/30 in type 2 diabetes patients of different race or ethnicity (INITIATEplus trial). Curr Med Res Opin. 2012;28(7):1203-11. doi:10.1185/ 03007995.2012.686444.

33. Zandieh SO, Goldmann DA, Keohane CA, Yoon C, Bates DW, Kaushal R. Risk factors in preventable adverse drug events in pediatric outpatients. J Pediatr. 2008;152(2):225-31. doi:10.1016/j. jpeds.2007.09.054.

34. Ghazi A, Landerman LR, Lien LF, Colon-Emeric CS. The impact of race on the incidence of hypoglycemic episodes in hospitalized older adults with type 2 diabetes. Clin Diabetes. 2013;31(2):66-72.

35. Queale WS, Seidler AJ, Brancati FL. Glycemic control and sliding scale insulin use in medical inpatients with diabetes mellitus. Arch Intern Med. 1997;157(5):545-52.

36. Diamantidis CJ, Seliger SL, Zhan M, Walker L, Rattinger GB, Hsu $\mathrm{VD}$, et al. A varying patient safety profile between black and nonblack adults with decreased estimated GFR. Am J Kidney Dis Off J National Kidney Found. 2012;60(1):47-53. doi:10.1053/j.ajkd. 2012.01.023.

37. Berkowitz SA, Karter AJ, Lyles CR, Liu JY, Schillinger D, Adler $\mathrm{NE}$, et al. Low socioeconomic status is associated with increased risk for hypoglycemia in diabetes patients: the Diabetes Study of Northern California (DISTANCE). J Health Care Poor Underserved. 2014;25(2):478-90. doi:10.1353/hpu.2014.0106.

38. Cengiz E, Xing D, Wong JC, Wolfsdorf JI, Haymond MW, Rewers A, et al. Severe hypoglycemia and diabetic ketoacidosis among youth with type 1 diabetes in the T1D Exchange clinic registry. Pediatr Diabetes. 2013;14(6):447-54. doi:10.1111/pedi.12030.

39. Johns C, Faulkner MS, Quinn L. Characteristics of adolescents with type 1 diabetes who exhibit adverse outcomes. Diabetes Educ. 2008;34(5):874-85. doi:10.1177/0145721708322857.

40. Lopez JM, Bailey RA, Rupnow MF, Annunziata K. Characterization of type 2 diabetes mellitus burden by age and ethnic groups based on a nationwide survey. Clin Ther. 2014;36(4):494-506. doi:10.1016/j.clinthera.2013.12.016.

41. Overstreet S, Holmes CS, Dunlap WP, Frentz J. Sociodemographic risk factors to disease control in children with diabetes. Diabet Med J Br Diabet Assoc. 1997;14(2):153-7. doi:10.1002/(SICI)10969136(199702)14:2<153::AID-DIA318>3.0.CO;2-K.

42. Palta M, LeCaire T, Daniels K, Shen G, Allen C, D'Alessio D. Risk factors for hospitalization in a cohort with type 1 diabetes. Wisconsin Diabetes Registry. Am J Epidemiol. 1997;146(8):627-36.
43. Canchi D, Baker T. Attitudinal differences in the perception and adherence to pain medication in older black and white cancer patients: results from the cancer pain management study. PsychoOncology. 2012;21(1):38.

44. Meghani SH, Kang Y, Chittams J, McMenamin E, Mao JJ, Fudin J. African Americans with cancer pain are more likely to receive an analgesic with toxic metabolite despite clinical risks: a mediation analysis study. J Clin Oncol Off J Am Soc Clin Oncol. 2014;32(25): 2773-9. doi:10.1200/JCO.2013.54.7992.

45. Thigpen JL, Q. Y, N. L, M. B, N.A. L. Racial differences in anticoagulation control and risk of hemorrhage among warfarin users. Pharmacotherapy. 2012;32(10):e189.

46. Sadhasivam S, Chidambaran V, Ngamprasertwong P, Esslinger HR, Prows $\mathrm{C}$, Zhang $\mathrm{X}$, et al. Race and unequal burden of perioperative pain and opioid related adverse effects in children. Pediatrics. 2012;129(5):832-8. doi:10.1542/peds. 2011-2607.

47. Jimenez N, Anderson GD, Shen DD, Nielsen SS, Farin FM, Seidel $\mathrm{K}$, et al. Is ethnicity associated with morphine's side effects in children? Morphine pharmacokinetics, analgesic response, and side effects in children having tonsillectomy. Paediatr Anaesth. 2012;22(7):669-75.

48. Okoroh JS, Uribe EF, Weingart S. Racial and ethnic disparities in patient safety. J Patient Saf. 2014. doi:10.1097/PTS. 0000000000000133.

49. McDowell SE, Coleman JJ, Ferner RE. Systematic review and meta-analysis of ethnic differences in risks of adverse reactions to drugs used in cardiovascular medicine. BMJ. 2006;332(7551): 1177-81. doi:10.1136/bmj.38803.528113.55.

50. Hohl CM, Kuramoto L, Yu E, Rogula B, Stausberg J, Sobolev B. Evaluating adverse drug event reporting in administrative data from emergency departments: a validation study. BMC Health Serv Res. 2013;13:473. doi:10.1186/1472-6963-13-473.

51. Field TS, Gurwitz JH, Harrold LR, Rothschild JM, Debellis K, Seger AC, et al. Strategies for detecting adverse drug events among older persons in the ambulatory setting. J Am Med Inform Assoc JAMIA. 2004;11(6):492-8. doi:10.1197/jamia.M1586.

52. Leonard CE, Haynes K, Localio AR, Hennessy S, Tjia J, Cohen A, et al. Diagnostic E-codes for commonly used, narrow therapeutic index medications poorly predict adverse drug events. J Clin Epidemiol. 2008;61(6):561-71. doi:10.1016/j.jclinepi.2007.08. 003.

53. Jha AK, Kuperman GJ, Teich JM, Leape L, Shea B, Rittenberg E, et al. Identifying adverse drug events: development of a computerbased monitor and comparison with chart review and stimulated voluntary report. J Am Med Inform Assoc JAMIA. 1998;5(3): 305-14.

54. Race, ethnicity, and language data: standardization for health care quality improvement. Washington, DC: Institute of Medicine Subcommittee on Standardized Collection of Race/Ethnicity Data for Healthcare Quality 2009.

55. Takahashi H, Wilkinson GR, Nutescu EA, Morita T, Ritchie MD, Scordo MG, et al. Different contributions of polymorphisms in VKORC1 and CYP2C9 to intra- and inter-population differences in maintenance dose of warfarin in Japanese, Caucasians and African-Americans. Pharmacogenet Genomics. 2006;16(2):10110.

56. Seligman HK, Davis TC, Schillinger D, Wolf MS. Food insecurity is associated with hypoglycemia and poor diabetes selfmanagement in a low-income sample with diabetes. J Health Care Poor Underserved. 2010;21(4):1227-33. doi:10.1353/hpu.2010. 0921.

57. Shea JA, Beers BB, McDonald VJ, Quistberg DA, Ravenell KL, Asch DA. Assessing health literacy in African American and Caucasian adults: disparities in rapid estimate of adult literacy in medicine (REALM) scores. Fam Med. 2004;36(8):575-81. 
58. Kangelaris KN, Bent S, Nussbaum RL, Garcia DA, Tice JA. Genetic testing before anticoagulation? A systematic review of pharmacogenetic dosing of warfarin. J Gen Intern Med. 2009;24(5):656-64. doi:10.1007/s11606-009-0949-1.

59. Sabir I, Khavandi K, Brownrigg J, Camm AJ. Oral anticoagulants for Asian patients with atrial fibrillation. Nat Rev Cardiol. 2014;11(5):290-303. doi:10.1038/nrcardio.2014.22.

60. Sarkar U, Karter AJ, Liu JY, Adler NE, Nguyen R, Lopez A, et al. The literacy divide: health literacy and the use of an internet-based patient portal in an integrated health system-results from the diabetes study of northern California (DISTANCE). J Health Commun. 2010;15 Suppl 2:183-96. doi:10.1080/10810730.2010.499988.
61. Brouwer ES, West SL, Kluckman M, Wallace D, Masica AL, Ewen E, et al. Initial and subsequent therapy for newly diagnosed type 2 diabetes patients treated in primary care using data from a vendorbased electronic health record. Pharmacoepidemiol Drug Saf. 2012;21(9):920-8. doi:10.1002/pds.2262.

62. Jacquez F, Stout S, Alvarez-Salvat R, Fernandez M, Villa M, Sanchez J, et al. Parent perspectives of diabetes management in schools. Diabetes Educ. 2008;34(6):996-1003. doi:10.1177/ 0145721708325155.

63. Hausmann LR, Gao S, Lee ES, Kwoh CK. Racial disparities in the monitoring of patients on chronic opioid therapy. Pain. 2013;154(1):46-52. doi:10.1016/j.pain.2012.07.034. 